\title{
Supporting Pre-Service Primary School Teachers with Hands-on-Science
}

\author{
Antonia Chimonidou \\ University of Texas at Austin
}

\author{
Randi R. Ludwig \\ Dell Technologies
}

\author{
Irina Marinova \\ University of Texas at Austin
}

The education that primary school students receive shapes their relationship with science. Elementary school teachers report they have low confidence and enthusiasm about teaching science. The Hands-onScience Program at UT Austin was created to serve the unique needs of Applied Learning and Development majors. HoS consists of four required content courses: Physics, Chemistry \& Geology, Biology, and Astronomy \& Earth Climate. HoS classes differ from traditional science courses in two ways: (1) method of instruction, and (2) content. Our students attain higher learning gains and display improved attitudes towards learning science, compared to students who take traditional science classes.

\section{INTRODUCTION}

How well do universities prepare pre-service teachers for teaching science? The National Commission on Teaching \& America's Future (1996) identified four serious limitations to pre-service teachers' career preparation: inadequate time to learn content, fragmentation of content areas and best practices for teaching in those areas, uninspired teaching methods, and superficial curriculum. Prior to 2009, students preparing for careers in elementary education at the University of Texas at Austin (UT Austin) were required to take any four introductory science courses through the College of Natural Sciences as part of their degree plan. While standard introductory science classes offer to teach students a wide range of topics within any given field, many science curricula are arguably superficial and have been criticized as being "a mile wide and an inch deep" (Schmidt et al., 1997). Many college students demonstrate deep-seated misunderstandings about basic scientific ideas in fields such as astronomy, physics, and biology to name a few (e.g., Schneps \& Sadler, 1989). In fact, Lightman \& Sadler (1993) show that while teachers in traditional classes can generally predict students' average incoming performance on astronomy assessments for example, they grossly over-predict the gains in student knowledge of basic astronomy concepts at the end of traditional courses. In addition to their broad content, traditional lecture classes represent a fragmented curriculum offered through different departments, often disconnected from one another. Yet, for students to attain deep understanding of these fundamental scientific principles, explicit connections between content areas and applications are necessary (e.g., Larkin et al., 1980; Gick \& Holyoak, 1980; Perfetto et al., 1983). Finally, large lecture classes are isolating environments where even involved students are constrained in their ability 
to engage with the instructor by many factors, such as physical distance, the number of students, and the impersonal environment (Geske, 1992). For pre-service teachers, who tend to lack confidence in their own knowledge of science (Young \& Kellogg, 1993; Ginns \& Foster, 1983), such an environment is, at best, not suited to adequately prepare them to be successful science teachers. For these many reasons, large, broad classes are not necessarily the most useful way to prepare pre-service elementary teachers to understand fundamental scientific concepts and how scientific principles are related across disciplines. These factors conspire to severely negatively impact their self-confidence in understanding and teaching science (Bandura, 1993).

The question is, with practical limits on funding, time, and space, can we do better? At UT Austin, the answer is: yes, we can!

In this paper, we outline the design and development of the Hands-on-Science (HoS) Program and our two data sets for subsequent program evaluation. We ask the question: do pre-service elementary school teachers, who need specific content knowledge and pedagogical skills for their future careers, benefit more from the HoS courses than they would in general science courses?

\section{COURSE DESIGN}

If we are to address the problems in STEM education in the U.S, more effective preparation of preservice elementary teachers is crucial. To better serve these future elementary teachers, the College of Natural Sciences at UT Austin, in conjunction with UTeach Natural Sciences, a nationally recognized secondary teacher preparation program, offers a four-course science sequence for education majors called Hands-on-Science (HoS), which is specifically tailored to the unique needs of this student population. This four-course sequence is required for all Applied Learning and Development majors and serves over 350 students per semester. The HoS program differs from traditional, introductory science classes in two main ways: through teaching methodology and through curriculum.

The HoS program is designed to be a melting pot of best practices for learning in general, and science in particular. Student understanding and the ability to flexibly use knowledge is increased by many factors, including multiple exposures to key ideas in many contexts (Bjork \& Richardson-Klavhen, 1989), explicitly eliciting misconceptions or naive reasoning (e.g., Confrey, 1990; Fitzsimmons et al., 1994; Resnick \& Klopfer, 1989), active-engagement such as hands-on learning and social learning interactions (McDermott, 1991; McDermott \& Shaffer, 1992; Prather et al., 2004). Because students come into any classroom with prior ideas and experience about the world, the constructivist framework of learning suggests that students may require exposure to many opportunities and contexts to fully integrate a concept into their way of thinking (Confrey, 1990). Thus, HoS courses provide environments where active learning is promoted in a hands-on, guided inquiry manner, utilizing all of the factors listed above, in addition to providing integrated science content so students get the chance to grapple with fundamental ideas in multiple contexts.

In preparing pre-service teachers, group work can be particularly important, so that students have the chance to practice teaching each other. Grouping students provides them with the opportunity to participate in the social interactions that provide multiple learning benefits (Mazur, 1997; Green, 2003). In groups, they can draw on the diverse skill sets of students within their groups to solve problems and collect data. These groups also give students the opportunity to share their ideas in a low-risk setting, making it more likely that students will acknowledge their true preconceptions about the topics at hand, and then share their collective thoughts in class-wide discussions. Employing groups within such studio-style classrooms promotes a transition from the traditional instructor as "sage on the stage", to the "guide by your side" (Prather et al., 2004; Fraknoi, 2011). Rather than deliverers of information, instructors within studio-style classrooms function as moderators for class discussion, who probe student knowledge and give students

helpful nudges in the right direction. Thus, the design of the HoS courses transforms the classroom into a learner-centered environment within a studio-style classroom, one of which is shown in Figure 1. 


\section{FIGURE 1 \\ PANORAMA OF A HOS STUDIO-STYLE CLASSROOM AT UT AUSTIN}

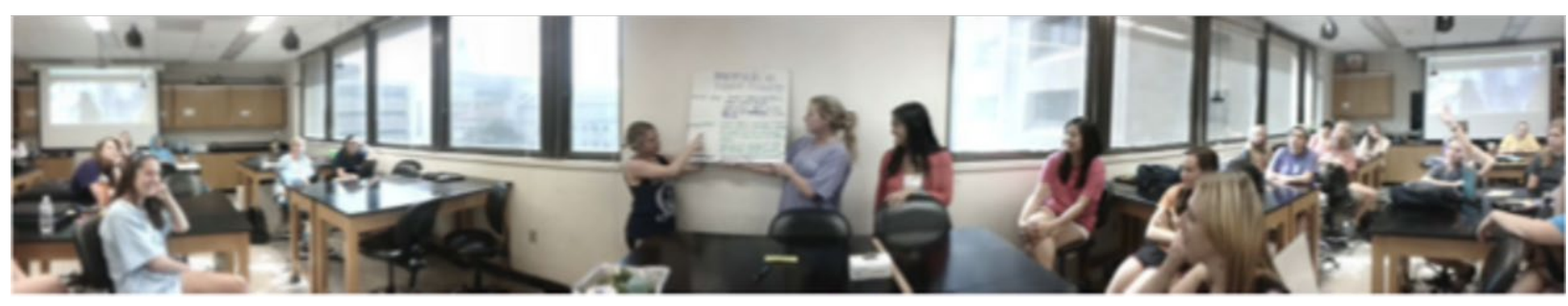

The structural framework for a typical HoS class period is based on the format presented in Physics and Everyday Thinking (Goldberg at al., 2008) where students are responsible for constructing their own content knowledge using experiments, discussion with peers, and a curriculum consisting of guiding questions. Each lesson begins with a few questions designed to elicit students' preconceptions or naive reasoning on the main topic of the day. Students then share their ideas with the class, so there is collective knowledge of many possible ways of thinking. Then the students perform data-gathering activities during which they are regularly asked to make predictions and connect trends to other concepts they have seen previously. In this way, the students are encouraged to form their own conclusions about the topic at hand, based on the data they have just seen, rather than accepting scientific principles simply by being told. Finally, each lesson ends with thought-provoking questions, which encourage students to use evidencebased reasoning to summarize the main ideas of the lesson and connect them to other contexts. These questions are the basis of in-class discussions, where students are responsible for presenting their ideas to the class and justifying and elaborating them for their peers. In addition to these methods of in-class instruction, students in the HoS program are tested for their understanding and ability to explain situations using scientific concepts. Since it is difficult to encourage higher-level thinking with multiple-choice tests based largely on declarative knowledge (Stanger-Hall, 2012), we format our summative assessments utilizing constructed-response questions requiring several sentences of explanation. These exams form the bulk of students' grades and emphasize that we value explanatory power over memorized, disconnected facts.

For example, prior to starting the chapter on Moon phases in our Astronomy course, a topic included in the Texas Essential Knowledge and Skills (TEKS) for elementary science, students are tasked with observing and recording the shape and position of the moon with respect to the Sun every day for an entire lunar cycle. The first lesson on Moon phases begins by asking students the following simple question: "What do you think causes Moon phases?" After students discuss this question in their group, they then share their ideas with the class. Student responses to the questions on Moon phases frequently involve the idea that Moon phases occur because the shadow of the Earth covers part of the Moon at different times of the month. Since the students have now become invested in the process of learning, this strategy ensures that they stay engaged and seek out the answers themselves during class. During the data-gathering part of the lesson, students are provided with Styrofoam balls on sticks to represent the Moon, inflatable globes to represent the Earth, and light bulbs to represent the Sun. They are guided through a variety of activities where they explore how the Moon can appear different as viewed from Earth, depending on its location with respect to the Earth and Sun. Not surprisingly, the experimental data collected is sometimes in agreement with the students' initial ideas, but often it is not. At this point, students are faced with the task of reconciling their incorrect ideas with the collected evidence, and as expected, this process is often frustrating and can take time. In this guided-inquiry learning environment, instructors provide guidance and support to help students iteratively modify their understanding, as needed. Finally, a summarizing question for the Moon phases activity might be the exact same question posed as an initial idea at the beginning of class. However, the students might now recognize how their original idea that "the Earth's shadow blocks the Moon when it is in the New Moon phase" is challenged by the fact that lunar eclipses are also caused by the Earth's shadow on the Moon, yet they are not observed every month. In this way, instead of being 
passive receivers of information, students become responsible for their own learning and for formulating their own explanations and conclusions based on the collected data.

Besides the learner-centered classroom dynamic and course design, the other major difference between traditional, introductory science courses and those offered through the HoS program is the curriculum itself. In addition to modeling best teaching practices, the HoS program is an integrated science curriculum spanning four semesters. Within these four semesters, the curriculum regularly links concepts across scientific disciplines to emphasize core principles that underlie many applications. For example, the HoS curriculum uses the idea of energy transfer as a unifying scientific concept, which underlies common physics principles such as conservation of energy, but is also used to explain earthquakes, photosynthesis, and seasons. Such integrated science concepts are referenced within the HoS curriculum with common terminology and familiar representations throughout all four semesters. While each semester is meant to tie across disciplines and incorporate integrated science content, the content focus in each of the four semesters is broadly organized in the following sequence: Semester 1: Physics, Semester 2: Chemistry \& Geology, Semester 3: Biology, Semester 4: Astronomy \& Earth Climate.

The HoS curriculum is a standards-based curriculum designed to focus on the concepts that these preservice teachers will be responsible for teaching in their own classrooms. Researchers have found that a large number of in-service elementary school teachers have many of the same misconceptions as their students (Atwood \& Atwood, 1996, 1997; Mant \& Summers, 1993). For pre-service elementary teachers to be effective when introducing their students to these topics, they need explicit instruction on these scientific concepts as part of their preparation. The broad topics we cover in the HoS curriculum are specifically selected to give the students a college-level, deep understanding of underlying concepts represented in the TEKS for grades K-8, with focus on K-5. Giving pre-service teachers a firm understanding of these topics now will hopefully enable them to teach such topics well and with confidence in the future.

\section{PROGRAM EVALUATION}

\section{Gains in Content Knowledge}

The HoS program incorporates a curriculum and method of teaching that is quite different from the introductory science courses that elementary education majors at UT took prior to 2009. How well do HoS students learn the science content they will be expected to teach, compared to students in the large lecture science courses they would have taken in the absence of the HoS program? To answer this question, we assess the impact of our inquiry-based, learner-centered classroom style coupled with the focused, integrated HoS curriculum on learning gains.

\section{Methodology}

To measure students' content gains, we administer pre- and post-assessments in a quasi-experimental design. The assessments are administered during the first and last week of the semester to both HoS classes and students in traditional introductory science classes. We utilize content assessments from the MOSART (Misconceptions-Oriented Standards-based Assessment Resources for Teachers) group, which are fieldtested, accredited assessment tools made up of multiple-choice items. The MOSART assessments are designed to include questions of varying difficulty levels, with attractive, research-based distractors, which allow us to probe for student misconceptions. Questions of varying difficulty levels allow for finer resolution when determining student achievement. The MOSART group makes tests available for grades $\mathrm{K}-4,5-8$, and 9-12 in physical science, Earth science, and astronomy, and grades $\mathrm{K}-4$ and 5-8 in life science. These assessments are based on the National Science Education Standards (National Research Council, 1996) for the appropriate grade levels. In our research, we utilize the six assessments designed for grades $\mathrm{K}-4$ and 5-8 for physical science, Earth science, and astronomy. These grade levels are chosen to be assessed since they contain the concepts that HoS pre-service teachers will be responsible for teaching to their own students. At the time of data collection, the MOSART life sciences assessments were 
unavailable, so to assess student changes in biology content, we also incorporate additional assessment items from past, grade 5 for science TAKS (Texas Assessment of Knowledge and Skills) tests.

As with all course development, we find that we simply cannot cover everything. Because our aim in this study is to determine whether these students are better served by having access to a program like HoS, we compare data sets for the subset of questions that we do address. HoS instructors independently selected questions from the six MOSART tests (plus additional TAKS questions for biology) that are represented in the HoS curriculum, and only those questions where all instructors agree that the content is covered in HoS are used. Despite the many reasons for using the MOSART questions as our assessment tool (see above), each of the assessments includes a variety of questions that are not addressed, directly or indirectly, in our curriculum. The HoS curriculum emphasizes concepts drawn from national and state science standards (NSES and TEKS) that we consider to be the most fundamental or most difficult for pre-service elementary teachers to go on to teach. For instance, we choose not to assess MOSART questions designed for grade levels 6-8, since these are not directly relevant to the content our future teachers will be responsible for teaching. Additionally, those questions not addressed reflect content that we feel is either too detailed to devote proper time to, or that HoS students will be able to learn for themselves given the skills and background they acquire in the HoS program. Consequently, our assessments include 15 questions for physics, 5 for chemistry, 11 for geology, 26 for biology, and 29 for astronomy.

In order to evaluate HoS students' performance in the context of relevant control groups, it is necessary for us to rely on the generosity of multiple instructors at UT Austin who are not associated with the HoS program. To avoid unnecessary class interference in these instructors' classes, we design our testing methodology to minimize the class time required and reduce the amount of paper necessary for testing. To maintain consistency, the same testing methodology is implemented in our HoS classes. Each student is provided with a scantron to record his/her responses and presented the assessment questions in a slideshow presentation. Depending on the length of the question, students in each group are given between 30-90 seconds to record their answer. Despite this seemingly short amount of time, the administrants wait for students to finish answering before moving on. At the end of the assessment, students are given the option to return to any questions that they wish to see again.

For each content area, we have a HoS treatment group and a corresponding control group from an appropriate traditional introductory science course, with the exception of geology (see note below). Our analysis only includes students for whom we have paired pre-test/post-test data. Our sample sizes for each group are reported in Table 1, along with the dates of data collection, and results for each group. Altogether, the treatment sample is comprised of a total of 879 students in the four HoS classes and the control group includes 503 students in appropriate traditional introductory science courses. (Note: the missing control group data for the geology assessment is due to unavailability of an appropriate introductory geology course at the time of data collection.)

\section{Content Results}

In Figure 2, we compare the pre- and post-test averages for the HoS treatment group (blue arrows) and the control group (red arrows) for each of the five content areas tested. The arrows point from the pre-test average to the post-test average for each sample. We note that, in all categories, the HoS students show significant $(\mathrm{p}<0.001)$ increases to their content knowledge after one semester of treatment. In contrast, the control groups show smaller or no gains during the same time interval for the content included on our assessments. 
FIGURE 2

AVERAGE STUDENT CONCEPTUAL CHANGES IN FOUR SCIENTIFIC DISCIPLINES

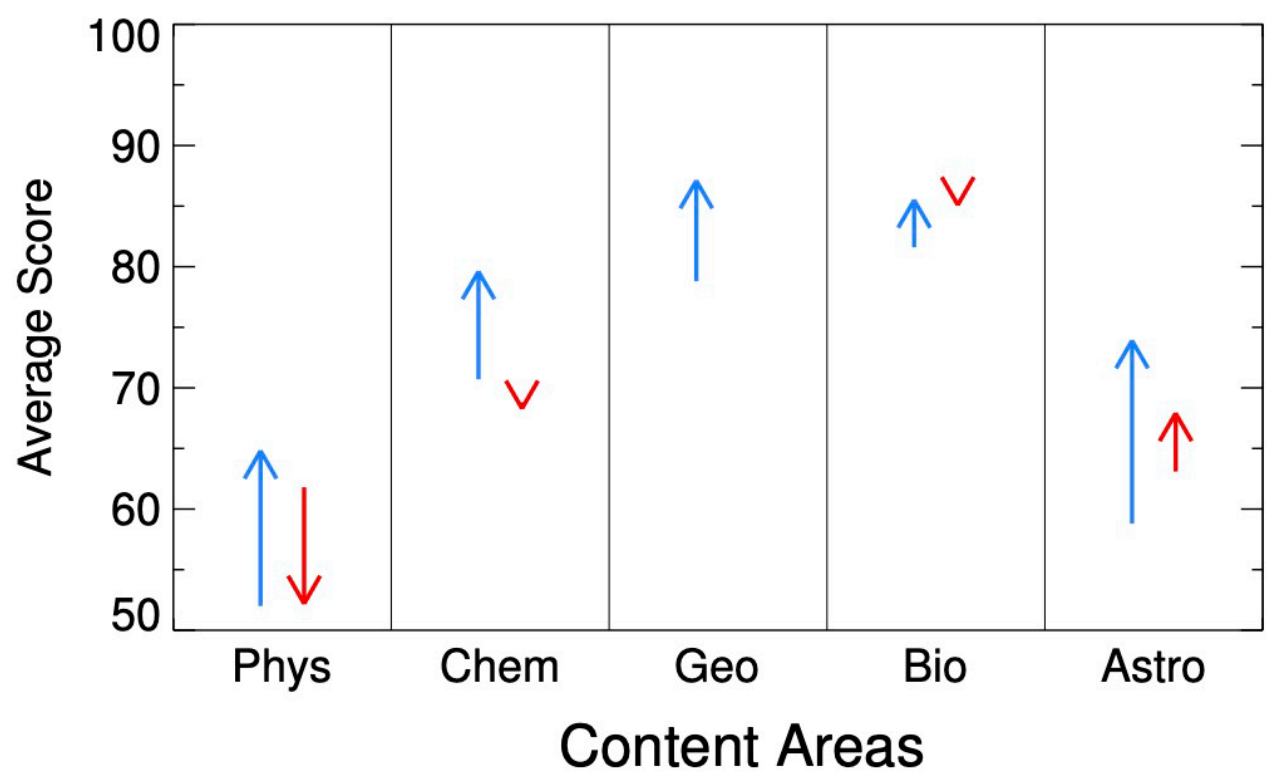

HoS students are shown in blue and students from the control group are shown in red. Arrows point from pre-to post-test averages. HoS students show significant gains in content knowledge while students in the control group show smaller or no gains.

An additional measure of the change in student performance is the normalized gain $<\mathrm{g}>$, which is defined as:

$<g>=\frac{<\text { post }>-<\text { pre }>}{100-<\text { pre }>}$

Thus, for a single student, $<\mathrm{g}>$ represents the change in the student's score as a fraction of the total possible improvement on that assessment. For example, if a student scores 50 of 100 possible points on the pre-test, he or she has room to improve by 50 points in the post-test. If that student then scores 75 of 100 points on the post-test, then he or she will have a normalized gain, $<\mathrm{g}>$, of 0.5 , meaning that student has increased his or her score by half of the possible amount. For sample averages, we calculate $<\mathrm{g}>$ as the room for improvement within a sample from the average pre-test score to the average post-test score. Table 2 presents the pre- and post-test averages as well as the $<\mathrm{g}>$ for each of the two groups and each of the five subjects included in the HoS curriculum.

In physics, the HoS students start from a lower pre-test average than the control group students (52\% as compared to $61.8 \%$ ) but reach a higher post-test average that the control group, obtaining a $\left\langle\mathrm{g}_{\mathrm{Hos}}\right\rangle=$ 0.27 . Note that the control group has a negative normalized gain after one semester, suggesting that for the items probed in this assessment, the control group students are more likely to answer incorrectly after taking the introductory physics class.

In both chemistry and biology, both the treatment and control groups start from similar pre-test averages of $\sim 70 \%$. For chemistry, the HoS students show a significant improvement of almost a letter grade $(9.2$ points), which corresponds to a $\left\langle\mathrm{g}_{\mathrm{HoS}}\right\rangle=0.30$. At the same time, the control group shows no improvement. On the biology assessment, HoS students again show improvement $\left(\left\langle\mathrm{g}_{\mathrm{HoS}}\right\rangle=0.21\right)$, while the control group students show no significant change.

For the astronomy assessment, both the HoS and the control group students show significant improvement on the content questioned. However, despite a lower pre-test average, the treatment group 
improves beyond the control group to a higher post-test average. While both sets of students improve, the $<\mathrm{g}>$ for the HoS students is almost three times higher than that of the control group students $\left(<\mathrm{g}_{\mathrm{HoS}}>=0.37\right.$ as compared to $<\mathrm{g}_{\text {Control }}>=0.13$ ).

Even though no control data is available for comparison for geology, it is still worthy to note that the HoS students attain a $<\mathrm{g}_{\mathrm{HoS}}>=0.39$ after treatment, even higher than the normalized gains observed in the other four subject categories.

TABLE 1

SAMPLE INFORMATION BY CONTENT AREA

\begin{tabular}{|c|c|c|c|c|c|c|c|c|c|c|}
\hline \multicolumn{6}{|c|}{ HANDS-ON-SCIENCE } & \multicolumn{5}{|c|}{ CONTROL GROUP } \\
\hline $\begin{array}{c}\text { Content } \\
\text { Area }\end{array}$ & $\mathbf{N}$ & Date & Pre & Post & $\langle\mathrm{g}\rangle_{\mathrm{HoS}}$ & $\mathbf{N}$ & Date & Pre & Post & $\langle\mathbf{g}\rangle_{\text {Control }}$ \\
\hline Physics & 337 & $\begin{array}{l}\text { SP11- } \\
\text { SP12 }\end{array}$ & 52.0 & 64.8 & 0.27 & 70 & F11 & 61.8 & 52.2 & -0.25 \\
\hline Chemistry & 336 & $\begin{array}{l}\text { SP11- } \\
\text { SP12 }\end{array}$ & 70.7 & 79.6 & 0.30 & 132 & F11 & 68.8 & 68.3 & -0.02 \\
\hline Geology & 336 & $\begin{array}{l}\text { SP11- } \\
\text { SP12 }\end{array}$ & 78.8 & 87.1 & 0.39 & - & - & - & - & - \\
\hline Biology & 118 & $\begin{array}{l}\text { SP11- } \\
\text { F11 }\end{array}$ & 81.6 & 85.5 & 0.21 & 191 & $\begin{array}{l}\text { SP11- } \\
\text { F11 }\end{array}$ & 85.3 & 85.1 & -0.01 \\
\hline Astronomy & 88 & $\begin{array}{l}\text { SP11- } \\
\text { F12 }\end{array}$ & 58.8 & 73.9 & 0.37 & 110 & F11 & 63.1 & 67.9 & 0.13 \\
\hline
\end{tabular}

Average pre-and post-test scores and normalized gain for HoS and control group students for all content areas covered in the HoS curriculum. (Note: the partially missing data for geology is due to difficulties in obtaining an appropriate control group for that subject at the time of data collection.)

In summary, the HoS students improve on all five content assessments, which specifically test knowledge the HoS students will be responsible to teach, and show higher normalized gains than the control groups for all content areas assessed. Thus, we confidently conclude that the HoS students benefit from higher increases in science content knowledge than they would have in traditional, introductory science courses, and are better prepared for their future careers as elementary school teachers by HoS courses.

\section{Positive Shift in Attitudes Towards Science}

Concurrent with data collection for our study of students' change in conceptual content knowledge, Riegle-Crumb et al. (2015) also investigated quantitative shifts in HoS students' attitude towards science. To examine this question, pre- and post-surveys were collected from 238 students enrolled in the HoS program and 263 students enrolled in traditional lecture-based introductory science courses. Both groups completed an online, 21-item Likert-scale survey about their attitudes toward science in general, and learning science in particular. While this 21 -question survey represents many different ideas students have about learning science, for simplicity Riegle-Crumb et al. classified the questions into four categories of similar ideas. The first category, confidence, represents students' confidence in their own abilities to solve problems, and includes four items like "I have always done well in science." The second category, enjoyment, looks at students' enjoyment of science and includes five items, such as "I like science." Items in the third category, anxiety, investigate the students' anxiety when confronted with situations related to science and include eight items where students are asked to rank how worried each situation makes them. An example item is "Walking on campus and thinking about a science course." Finally, the fourth category, relevance, represents the students' conceptions of the utility or relevance of science to everyday life with four statements, including "The subject of science is not very relevant to most people."

For each category, Riegle-Crumb et al. compared the average student pre-test and post-test responses for both students in the HoS program and those enrolled in traditional introductory, lecture-based courses. 
Results of paired $t$-tests indicate a statistically significant improvement over time for each area for the HoS students, while students in the control group do not show those trends. Figure 3 (reprinted with permission from Riegle-Crumb et al., 2015) shows the changes over time for each attitudinal outcome and each group.

\section{FIGURE 3 ADJUSTED PRE AND POST MEAN ATTITUDE CHANGES FOR HoS AND CONTROL}
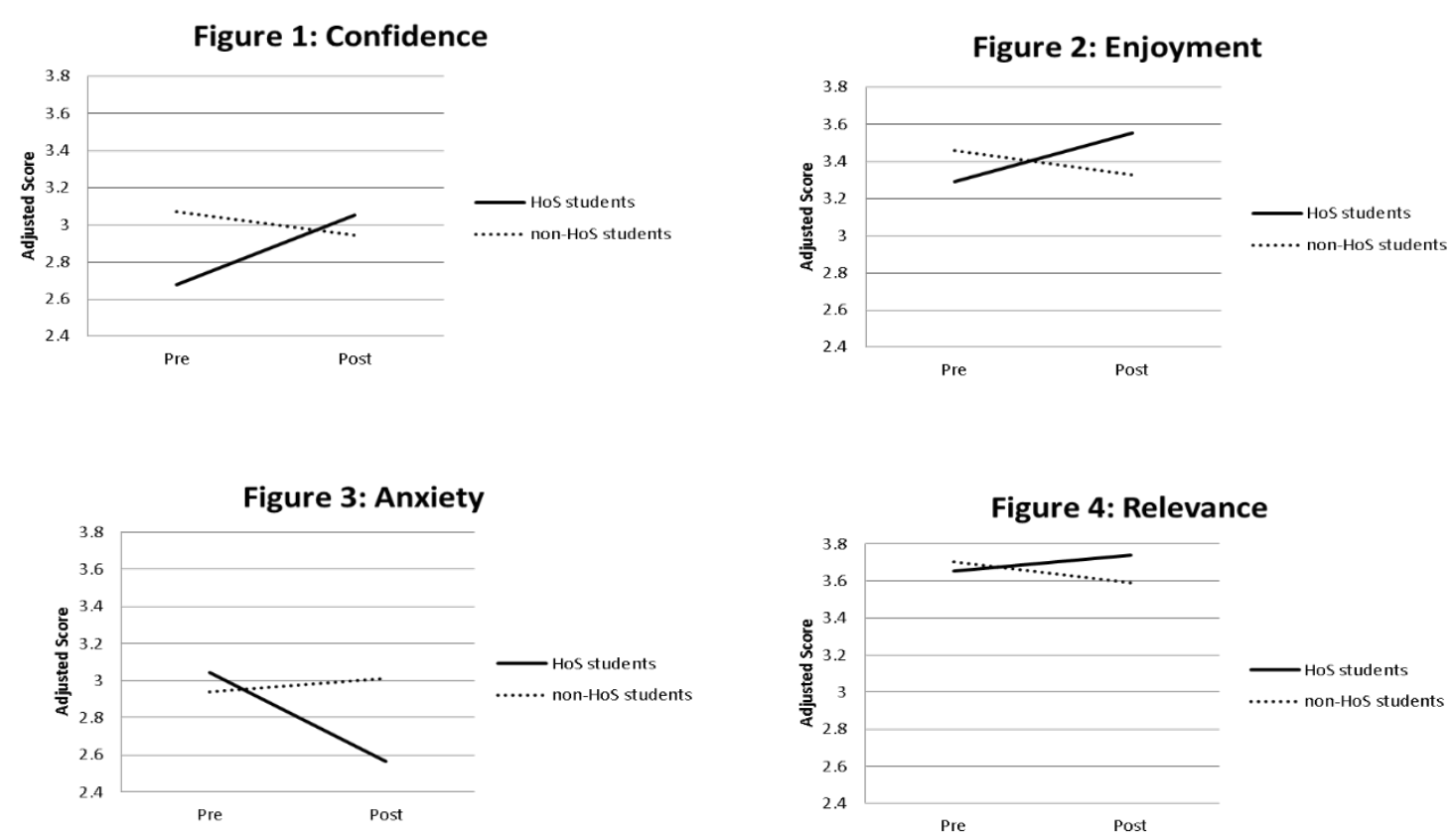

Figures 1-4 (reprinted with permission from Riegle-Crumb at el., 2015) show the adjusted pre-and post-Likert scale means for four attitude categories. HoS students are shown as solid lines and control group students are shown as dotted lines.

The data analyses reveal a remarkably consistent and positive story for HoS students; students significantly changed their views toward science from the pre- to the post-survey, such that after participating in inquiry-based content courses, they reported more confidence in their skills as science learners, more enjoyment and less anxiety toward science, and perceived it as more relevant. Conversely, patterns for those in the comparison group revealed a decline in favourable attitudes toward science after enrolling in a traditional lecture-based science course. Given that the control group represents students in the very courses that HoS students would have taken in the absence of the HoS program, we can confidently say that we have demonstrably improved the preparation experience for these pre-service teachers compared to their previous degree requirements.

\section{DISCUSSION AND CONCLUSIONS}

Encouraging students to think scientifically and promoting their enthusiasm for science will increase the chances of students choosing careers in science or supporting scientific research. Future workers need to be adequately prepared to enter burgeoning technical fields. These workers typically come from college majors in various STEM fields. The U.S. Department of Labor suggests that preparing future workers to enter STEM fields can have long-term effects on the standard of living in the U.S. and employment opportunities for several decades (Jobs for the Future, 2007). The National Research Council suggests that a major factor in preparing students for STEM fields lies in "improving K-12 science and mathematics education" (Rising Above the Gathering Storm Committee, 2010). 
Because many educators teach in the same manner that they are taught, it is important to educate future teachers using methodology that will encourage best practices in their own classrooms. Unfortunately, students who are pre-service teachers largely enter college with the beliefs that science is inaccessible and stressful (Otero \& Gray, 2008; Riegle-Crumb et al., 2015; Udo et al., 2004). Furthermore, they feel low confidence in their ability to learn science and therefore do not enjoy learning science (Skamp, 1991; Liang $\&$ Gabel, 2005). These issues are compounded by the fact that once these students become teachers themselves, their negative feelings toward learning science makes them less likely to engage their students with effective science instruction (Appleton \& Kindt, 1999; Otero \& Nathan, 2008).

Furthermore, by eighth grade, primary school students are making enrollment decisions that determine their effective ability to participate in a STEM major in college (Akos et al., 2007). While young elementary school students report that science is valuable and understandable, at some point in grades 4-8, many students lose their enthusiasm (Neathery, 1997). Yet it is this very enthusiasm and interest in science that is vital to increasing the number of students who go on to careers in STEM fields (Business-Higher Education Forum, 2010). In light of these many factors, it is important to prepare pre-service elementary school teachers in such a way that they can retain the enjoyment and excitement of scientific discovery while teaching their students.

The HoS program at UT Austin is a shining example of how courses - designed and implemented according to evidence-based science education research - can produce real benefits for pre-service teachers. Compared to control courses that represent the alternative classes these pre-service teachers could have taken for their science credits, we show that HoS students outperform control group students on the overall content in all four content areas compared, by up to three times as much! Additionally, Riegle-Crumb at al. (2015) show that students in the HoS program have improved attitudes in all areas, including higher confidence, lower anxiety, greater enjoyment of science, and consider science to be more useful in their daily lives. The students in traditional introductory courses experience either no change or more negative attitudes. The learning gains and positive attitude shifts towards learning science will, in turn, impact their future students.

The HoS program shows that universities can do more to better prepare their elementary education majors, even though such initiatives require more effort and financial commitment. The vast body of education research supports the idea that the improvements in learning gains and attitudes that we see in our students after going through the HoS sequence are due to students having more time-on-task, increased student participation and discussion, elicitation of pre-conceptions, and emphasis of evidence-based reasoning. Otero \& Gray (2008) also test this idea in 9 institutions of higher education across the country which use the Physics and Everyday Thinking curriculum (the model that HoS was based on) in physics classes of various sizes. In agreement with our results, they find that students using this inquiry-based and learner-centered curriculum had increased learning gains over students in traditional physics courses. But is this model able to be scaled up for large classes? Price et al. (2014) present a new iteration of the Physics curriculum, "Next Generation Physics and Everyday Thinking" with methods for use in large physics classes. It's possible to envision a teacher preparation program that is similar to HoS, using inquiry-based teaching methods and a targeted and integrated curriculum, but flexible enough to be used in large classes. In fact, our next steps in developing the HoS program will be focused on replication at other universities. During the last decade, UTeach Natural Sciences has been successful in replicating their secondary teacher preparation program in 46 universities across the nation, and we hope to utilize their experience to extend this effort to improve primary STEM education in the same way with HoS.

\section{ACKNOWLEDGEMENTS}

We would like to acknowledge the vision and creativity of Drs. Sacha Kopp and Cynthia LaBrake, who first conceived the idea of the HoS program at UT Austin. We thank the National Science Foundation for the generous grant that made the implementation of the program possible as well as the College of Natural Sciences at UT Austin which is currently supporting its continued success. In addition, we would like to acknowledge the hard work of all members of the HoS team, instructors, coordinators, and learning 
assistants included, who continually strive to improve the education experience for students at UT. Without their vision and leadership, such a change would never have been possible. Finally, we would also like to thank the many faculty who allowed us to consume valuable class time administering assessments and surveying students.

\section{REFERENCES}

Akos, P., Shoffner, M., \& Ellis, M. (2007). Mathematics Placement and the Transition to Middle School. Professional School Counseling, 10(3), 238-244.

Appleton, K., \& Kindt, I. (1999). Why teach primary science? Influences on beginning teachers' practices. International Journal of Science Education, 21(2), 155-168.

Atwood, R., \& Atwood, V. (1996). Preservice elementary teachers' conceptions of the causes of seasons. Journal of Research in Science Teaching, 33(5), 553-563.

Atwood, R., \& Atwood, V. (1997). Effects of Instruction on Preservice Elementary Teachers' Conceptions of the Causes of Night and Day and the Seasons. Journal of Science Teacher Education, 8(1), 1-13.

Bandura, A. (1993). Perceived Self-Efficacy in Cognitive Development and Functioning. Educational Psychologist, 28(2), 117-148.

Bjork, R.A., \& Richardson-Klavehn, A. (1989). On the puzzling relationship between environmental context and human memory. In C. Izawa (Ed.), Current issues in cognitive processes: The Tulane Flowerree Symposium on Cognition (p.313344).

Confrey, J. (1990). Chapter 8: What Constructivism Implies for Teaching. Journal for Research in Mathematics Education. Monograph, 4, 107-210.

Fitzsimmons, S.J., \& Kerpelman, L.C. (1994). Teacher Enhancement for Elementary and Secondary Science and Mathematics: Status, Issues, and Problems.

Fraknoi, A. (n.d.). Seven Concepts for Effective Teaching. Astronomy Education Review, 10(1), 10401-3.

Geske, J. (1992). Overcoming the Drawbacks of the Large Lecture Class. College Teaching, 40(4), 151154.

Gick, M., \& Holyoak, K. (1980). Analogical problem solving. Cognitive Psychology, 12(3), 306-355.

Ginns, I., \& Foster, W. (1983). Preservice elementary teacher attitudes to science and science teaching. Science Education (Salem, Mass.), 67(2), 277-282.

Goldberg, F., Robinson, S., \& Otero, V. (2008). Physics \& everyday thinking / Fred Goldberg, Steve Robinson, Valerie Otero. It's About Time, Herff Jones Educational Division.

Green, P. (2003). Peer Instruction for Astronomy. Prentice Hall Series in Educational Innovation (Pearson Education).

Larkin, J., McDermott, J., Simon, D., \& Simon, H. (1980). Models of Competence in Solving Physics Problems. Cognitive Science, 4(4), 317-345.

Liang, L., \& Gabel, D. (2005). Effectiveness of a Constructivist Approach to Science Instruction for Prospective Elementary Teachers. International Journal of Science Education, 27(10), 11431162.

Lightman, A., \& Sadler, P. (1993). Teacher predictions versus actual student gains. The Physics Teacher, $31(3), 162-167$.

Mant, J., \& Summers, M. (1993). Some primary-school teachers' understanding of the Earth's place in the universe. Research Papers in Education, 8(1), 101-129.

Mazur, E. (1997). Peer instruction: A user's manual / Eric Mazur. Prentice Hall.

McDermott, L. (1991). Millikan Lecture 1990: What we teach and what is learned-Closing the gap. American Journal of Physics, 59(4), 301-315.

McDermott, L., \& Shaffer, P. (1992). Research as a guide for curriculum development: An example from introductory electricity. Part I: Investigation of student understanding. American Journal of Physics, 60(11), 994-1003. 
National Academies Press. (2010). Rising above the gathering storm, revisited: Rapidly approaching category 5. Medicine, Engineering, \& Sciences Committee, 2.

National Commission on Teaching \& America's Future. (1996). What matters most: Teaching for America's future: Report of the National Commission on Teaching \& America's Future. The Commission.

National Research Council. (1996). National Science Education Standards: Observe, interact, change, learn. National Academy Press.

Neathery, M.F. (1997). Elementary and Secondary Students' Perceptions toward Science: Correlations with Gender, Ethnicity, Ability, Grade, and Science Achievement. Electronic Journal of Science Education, 2(1).

Otero, V., \& Gray, K. (2008). Attitudinal gains across multiple universities using the Physics and Everyday Thinking curriculum. Physical Review Special Topics. Physics Education Research, $4(2)$.

Otero, V., \& Nathan, M. (2008). Preservice elementary teachers' views of their students' prior knowledge of science. Journal of Research in Science Teaching, 45(4), 497-523.

Perfetto, G., Bransford, J., \& Franks, J. (1983). Constraints on access in a problem solving context. Memory \& Cognition, 11(1), 24-31.

Prather, E., Slater, T., Adams, J., Bailey, J., Jones, L., \& Dostal, J. (n.d.). Research on a Lecture-Tutorial Approach to Teaching Introductory Astronomy for Non-Science Majors. Astronomy Education Review, 3(2), 122-136.

Price, E., Goldberg, F., Robinson, S., Harlow, D., McKean, M., Keene, S., \& Czarnocki, K. (2014). Development and Evaluation of a Large-Enrollment, Active-Learning Physics Curriculum. In P.V. Engelhardt, A.D. Churukian, \& D.L. Jones (Eds.), Proceedings of the 2013 Physics Education Research Conference (pp. 285-289).

Resnick, L., \& Klopfer, L. (1989). Toward the thinking curriculum: Current cognitive research, edited by Lauren B. Resnick \& Leopold E. Klopfer. ASCD.

Riegle-Crumb, C., Morton, K., Moore, C., Chimonidou, A., Labrake, C., \& Kopp, S. (2015). Do Inquiring Minds Have Positive Attitudes? The Science Education of Preservice Elementary Teachers. Science Education (Salem, Mass.), 99(5), 819-836.

Schmidt, W.H., McKnight, Curtis C., Raizen, S., Jakwerth, P., Valverde, G., ... Houang, R.T. (1997). A splintered vision: An investigation of U.S. science and mathematics education. Journal for Research in Mathematics Education, 28(5), 628.

Schneps, M., \& Sadler, P. (1989). A Private Universe. Pyramid Films.

Skamp, K. (1991). Primary science and technology: How confident are teachers? Research in Science Education (Australasian Science Education Research Association), 21(1), 290-299.

Stranger-Hall, K.F. (2012). Multiple-Choice Exams: An Obstacle for Higher-Level Thinking in Introductory Science Classes. Life Sciences Education, 11(3).

U.S. Department of Labor. (2007). The STEM workforce challenge the role of the public workforce system in a national solution for a competitive Science, Technology, Engineering, and Mathematics (STEM) workforce / [prepared by Jobs for the Future].

Udo, M.K., Ramsey, G.P., \& Mallow, J.V. (2004). Science Anxiety and Gender in Students Taking General Education Science Courses. Journal of Science Education and Technology, 13(4), 435446.

Young, B., \& Kellogg, T. (1993). Science attitudes and preparation of preservice elementary teachers. Science Education (Salem, Mass.), 77(3), 279-291. 